\title{
Me \& my veggies: the use of interactive, personalised picture books in healthy eating interventions
}

Article

Accepted Version

Dulay, K. M., Masento, N., Harvey, K., Messer, D. J. and Houston-Price, C. (2020) Me \& my veggies: the use of interactive, personalised picture books in healthy eating interventions. Nutrition Bulletin, 45 (1). pp. 51-58. ISSN 14719827 doi: https://doi.org/10.1111/nbu.12415 Available at https://centaur.reading.ac.uk/88030/

It is advisable to refer to the publisher's version if you intend to cite from the work. See Guidance on citing.

To link to this article DOI: http://dx.doi.org/10.1111/nbu.12415

Publisher: Wiley-Blackwell

All outputs in CentAUR are protected by Intellectual Property Rights law, including copyright law. Copyright and IPR is retained by the creators or other copyright holders. Terms and conditions for use of this material are defined in the End User Agreement.

www.reading.ac.uk/centaur 
Central Archive at the University of Reading

Reading's research outputs online 
Me \& My Veggies: The Use of Interactive, Personalised Picture Books in Healthy Eating Interventions

\author{
Dulay, Katrina May ${ }^{1}$ \\ Masento, Natalie A. ${ }^{1}$ \\ Harvey, Kate ${ }^{1}$ \\ Messer, David J. ${ }^{2}$ \\ Houston-Price, Carmel $^{1}$
}

${ }^{1}$ School of Psychology and Clinical Language Sciences, University of Reading, United Kingdom

${ }^{2}$ Centre for Research in Education and Educational Technology, Open University, United Kingdom

Correspondence: Prof. Carmel Houston-Price, Professor of Language \& Cognitive Development, School of Psychology and Clinical Language Sciences, University of Reading, Harry Pitt Building, Earley Gate, Reading, United Kingdom RG6 6AL. Email: c.houstonprice@ reading.ac.uk

Acknowledgements: The work was supported by EIT Food Horizon 2020 funding. The content of the review reflects the views of the authors alone.

Conflict of interest: No conflicts of interest have been declared. 


\begin{abstract}
Increased fruit and vegetable consumption is important for children's healthy eating. Although repeated taste exposures are effective in supporting children's acceptance of healthy foods, more enjoyable interventions that increase children's familiarity with foods through other sensory modalities can also be helpful. Picture book interventions, which draw on the principles of visual familiarity and social reinforcement, are effective in increasing preschoolers' acceptance of vegetables. With the rise of digital technologies, e-books present a new tool for offering picture book interventions on a large scale, and offer additional features that might potentially boost their effects. In this paper, we propose two specific mechanisms, interactive learning and personalisation, that could make e-book eating interventions especially effective with young children and we outline new directions for research to elucidate their effects. We then briefly describe an ongoing study that explores the effectiveness of a vegetable e-book intervention that incorporates the mechanisms described in this paper.
\end{abstract}

Keywords: e-books, picture books, fruit and vegetable consumption, visual familiarity, personalisation, interactive learning 
Me \& My Veggies: The Use of Interactive, Personalised Picture Books in Healthy Eating Interventions

In 2017, only $18 \%$ of British children between 5 to 15 years old ate the recommended 5 portions of fruit and vegetables a day (NatCen Social Center, 2018). Increased consumption of these food groups is the World Health Organization's primary target for improving children's diets (World Health Organization, 2019). Children's food preferences develop early in childhood, and these early preferences predict dietary variety in later years, making the preschool years a critical period for instilling healthy eating habits (Coulthard et al. 2010). Repeated exposure to the taste of a food is an oft-recommended strategy to increase familiarity and liking of fruits and vegetables (NHS, 2018). However, as many as 10 to 15 tastes may be needed for children to accept new foods into their diets (Birch et al. 1987), while parents typically make only 3 to 5 attempts before deciding that a food is disliked and giving up (Carruth et al. 2004).

Many parents, therefore, do not provide sufficient taste exposures to bring about food acceptance, implying a need for alternative strategies to increase healthy food consumption. Several have been proposed, including 'sensory play', or engaging with the sensory properties of foods before they are introduced at mealtimes (Dazeley et al. 2012; Dazeley \& Houston-Price 2015; Hoppu et al. 2015; Coulthard \& Sealy 2017; Kähkönen et al. 2018). Another easy and enjoyable approach that has been found to be effective with preschoolers is looking at picture books about unfamiliar or disliked foods (Heath et al. 2011, 2014; de Droog et al. 2014; Owen et al. 2018; Houston-Price et al. 2019). This method serves to increase the child's visual familiarity with the food and its origins, and may additionally provide social reinforcement from the positivity of the adult reading the book, without requiring the child to eat the food when it is 
being familiarised. In this paper, we consider the evidence relating to the effectiveness of picture book interventions for increasing preschoolers' vegetable intake, and we consider the potential value of presenting picture book interventions in a digital format. Specifically, we consider the unique features and capabilities of e-books that might potentially further increase children's familiarity and positive engagement with the content, facilitating their acceptance of the targeted foods. First, we summarize previous studies that have used picture books or other visual stimuli to familiarise young children with fruits and vegetables. Then, we consider two specific mechanisms that e-books could harness to encourage healthy eating behaviours among children: interactive learning and personalisation.

\section{Picture book interventions for healthy eating}

Several studies have explored the potential for picture books to encourage fruit and vegetable consumption in preschool children between 21 months and 6 years of age. One approach has been to use story books involving character-led narratives that promote positive messages about vegetables such as kohlrabi, carrots and celeriac (Byrne \& Nitzke 2002; de Droog et al. 2014; Droog et al. 2017; Nekitsing et al. 2019). For example, de Droog et al. (2014) wrote a book about a character (a rabbit or turtle) who became fit and strong after eating carrots. In these studies, children were more accepting of the targeted vegetable following exposure to the story about it (Byrne \& Nitzke 2002; de Droog et al. 2014; Nekitsing et al. 2019).

Another approach has been to develop picture books depicting the 'farm to fork' journey of different foods through a combination of photographs and factual information (Houston-Price $e t$ al. 2009a, 2009b, 2019; Heath et al. 2014; Barnes \& Warren 2017; Owen et al. 2018). In these studies, repeated readings of picture books have been shown to influence outcomes including 
children's looking preferences towards targeted foods, and their willingness to taste, liking, and intake of the pictured foods. For example, Owen et al. (2018) provided families with a fruit or vegetable picture book that contained 6 pages of photographs and simple information about a food, from its origins in the farmer's field to the meal on the child's plate. In the We Love Broccoli book, for example, children were shown what broccoli looks like, how it grows, where it can be purchased, how it is prepared, and how it can be eaten raw or cooked. To evaluate the effects of these books, Owen et al. asked 127 parents of 18- to 24-month-olds to look at a picture book about a disliked or unfamiliar vegetable with their child every day for two weeks, and then invited parents to try to introduce this targeted food and a second disliked/unfamiliar vegetable into the child's diet. Results showed an increased liking and intake of the targeted vegetable following the picture book intervention. Positive changes in acceptance of the targeted vegetables were maintained for at least 3 months after the intervention had ended. Reporting on the same study, Houston-Price et al. (2019) demonstrated how much easier parents found the process of offering repeated tastes of a vegetable if their child had seen a book about it. In a similar study, changes in the acceptance of foods were shown to be strongest for vegetables that were unfamiliar to children before the picture book intervention started (Heath et al. 2014).

To date, little effort has been made to understand exactly how picture books work to change children's food acceptance. However, it is likely that multiple mechanisms underlie the observed effects, including visual familiarity and social reinforcement (Houston-Price et al. 2009b; de Droog et al. 2014; Heath et al. 2014; Droog et al. 2017; Nekitsing et al. 2019). In the next section, we consider how these and other mechanisms might be combined to build even more effective picture book interventions. 


\section{Mechanisms underpinning the effects of picture book interventions}

Although there are few direct investigations of the mechanisms that support the positive effects of picture books on children's acceptance of targeted foods, recent studies have identified several factors likely to play a role. Of course, increased visual familiarity is likely to be a key driver of children's willingness to taste and consume fruit or vegetables after looking at picture books about them. This hypothesis is supported by studies that demonstrated visual familiarity effects resulting from alternative presentation formats. Birch et al. (1987) found that children who merely looked at real fruits demonstrated enhanced ratings of how much they liked the fruits before they were asked to taste them. Interestingly, another study found that showing 3- to 6-year-old children simple pictures of vegetables over a two-week period increased their willingness to try those vegetables, even when the presented vegetables were unusually coloured, and therefore, relatively unfamiliar (Rioux et al. 2018). Therefore, repeated visual presentations do not only serve to increase children's familiarity with a food's appearance; they also enhance children's interest in these foods (Heath et al. 2011).

Reading picture books about foods could also provide opportunities for socially-rewarding interactions, thereby enhancing positive attitudes towards the foods described. de Droog et al. (2014) found that an interactive reading style that encouraged children to answer questions about their vegetable story resulted in greater consumption of carrots compared to a passive reading activity. In a follow-up study, it was found that interactive reading involving a puppet resulted in the highest intake of carrots across conditions (de Droog et al. 2017). The authors suggested that this reading style encouraged children to imitate the food-related behaviours modelled by the puppet, such as putting a carrot in its mouth, which served to reinforce the intended behaviour change. 
In other studies, visual familiarity has been combined with other strategies to support children's healthy eating. Sensory play with foods involves not only looking, but also listening, feeling, and smelling the food. On its own, sensory play outside of mealtimes has been shown to increase acceptance of unfamiliar vegetables at mealtimes for children aged 12 to 36 months (Dazeley \& Houston-Price 2015). Nekitsing et al. (2019) found that children aged 2 to 5 years old who took part in an intervention incorporating both sensory play and looking at a picture book about an unfamiliar vegetable (celeriac) were more likely to try celeriac compared to children who engaged in similar activities with a different vegetable. Others have developed interventions based on a combination of visual familiarity, reward, and modelling. For example, Farrow et al. (2019) found that the use of a mobile application involving vegetable-based games and activities increased 3- to 6-year-old children's liking for and intake of these foods compared to use of a non-food-related app.

In sum, recent research suggests that combining visual familiarity with engaging, interactive learning methods that familiarise children to foods through a range of sensory modalities could yield even greater impacts on children's acceptance of fruits and vegetables than visual exposure alone. However, programmes that require supporting materials (e.g. puppets) or access to hands-on activities (e.g. sensory play) may be difficult to implement on a large scale. In contrast, a well-designed e-book intervention could be made available on a wide scale and easily incorporated into routine activities within homes or childcare settings. In the next section, we consider the potential for e-books to capitalise on the various factors thought to influence children's eating behaviours. 


\section{The potential for e-books to enhance healthy eating interventions}

Children's use of iPads, Android tablets, and other mobile devices for reading purposes has risen sharply over the past decade (Korat \& Falk 2019). A national survey of 1,511 UK parents revealed that more than $80 \%$ of families with 0 - to 8 -year-olds own a smartphone and/or a tablet device (Kucirkova \& Littleton, 2016). Based on the results of the survey, the proportion of children who use a smartphone rises from around $50 \%$ of 0 - to 2-year-olds to $70 \%$ (smartphones) and $80-85 \%$ (tablet devices) among older age groups. Although parents reported an overall preference for print books over e-books when children are reading for pleasure or educational purposes, $62 \%$ of parents in this study requested advice on how interactive e-books could be used to support their children's learning. Specifically, parents wanted to know how to make the most of the features of e-books that differ from those of print books.

E-books introduce new possibilities in terms of both new content types (including audiovisual content) and new opportunities for interaction (including customisation features). Here we discuss two specific mechanisms by which e-books might enhance the effectiveness of picture book interventions for healthy eating. The first is interactive learning: parents and children can extend the content of the e-books through shared book-reading conversations and through the additional functionalities available to engage with the food-related content in new ways. The second is personalisation: e-books can be customised to add content that is personally relevant to children and their families. With these two mechanisms in mind, we consider the empirical evidence relating to aspects of e-book reading that enhance and hinder children's learning, and propose that future research should investigate whether e-book interventions support healthy eating in line with our hypotheses. 


\section{Interactive learning}

E-books, similar to printed books, can be used to support children's understanding of the world and help them acquire the language they need to describe it (de Jong \& Bus 2004; Zucker et al. 2009). Toddlers between 24 to 30 months have been shown to transfer new names for pictures they have encountered in an e-book to objects in real life and to pictures in printed books (Strouse \& Ganea 2017b).

Direct comparisons of children's learning during independent e-book reading versus when read printed picture books by an adult have yielded mixed results. For example, in one study, kindergarten children did not recall as many story elements or language structures from e-books as they did when stories were read to them by adults (de Jong \& Bus 2002). However, another study found comparable comprehension and vocabulary outcomes in the two conditions (de Jong \& Bus 2004). Some studies have directly compared learning from printed books versus e-books when both are read to the child by an adult. In one such study, children demonstrated superior learning gains in emergent literacy skills from e-books provided with adult instruction compared to an identical condition using a printed book (Segal-Drori et al. 2010). In another study, motherchild reading of e-books and print books demonstrated similar advantages in children's language skills compared to a control condition; however, the authors noted that parents in both intervention groups received similar suggestions for activities that would have minimised the differences between e-books and printed books (Korat \& Shamir 2013). These studies suggest a distinction between two types of interactivity afforded by e-books: the opportunity for the child to engage with features of e-books themselves, and the opportunity for adult-child interactions around the content of e-books. Understanding the effects of these two types of interactivity is key to designing high-quality e-books for healthy eating interventions. 
Available evidence suggests that some aspects of e-book interactivity are more helpful than others. Regarding the interactivity afforded by the medium, mobile iPod and iPad devices encourage more looking and touching behaviours among 4-year-old children than tabletop touchscreen computers (Roskos et al. 2014). Electronic reading also results in longer reading times (Grimshaw et al. 2007) and more frequent interactions with animations (de Jong \& Bus 2004). E-books also permit audio narration to accompany the text, which has been shown to facilitate story comprehension among 9- to 10-year-olds (Grimshaw et al. 2007), while the inclusion of animation cues supports kindergarten children's vocabulary development (Smeets \& Bus 2015). However, not all e-book features are helpful. Unrelated animations, games, and sounds have been found to serve as distractions to reading (Moody 2010) and to negatively impact on children's story comprehension (Parish-Morris et al. 2013). Taken together, these findings indicate that interactive e-books can elicit higher levels of motivation and engagement among children, resulting in longer exposure times and learning about the content. However, care is needed to minimize unnecessary features and to encourage engagement with those that facilitate learning.

In terms of adult-child interactions, findings are mixed about the effectiveness of e-books in facilitating high-quality talk between adult-child dyads. Some studies have found higher levels of child-initiated talk and responsiveness when reading e-books compared to print books (Korat \& Or 2010; Strouse \& Ganea 2017a). Others have found traditional books to be more effective in facilitating parental discourse and expanding talk (Korat \& Or 2010) and to elicit more contentfocused reading (Parish-Morris et al. 2013), while interactive e-books encourage more behaviour-focused talk (e.g. "Stop pressing the buttons!”; Parish-Morris et al. 2013). This disadvantage in the quality of parent-child talk during e-book use might be offset by providing 
guidance on how to use e-books effectively and by encouraging parents to talk about the fruits and vegetables featured in the stories.

As previous investigations have shown, children's interactive learning from e-books can be gained through information provided by the e-books themselves or through adult-child talk around the e-books. Both sources of information may have a function in healthy eating interventions. We also suspect that there may not be clear differences in the effectiveness of ebooks and printed books in such interventions, as positive effects are more likely to depend on the quality of the e-book content and of the adult-child interaction. Nevertheless, e-books offer two important advantages over written books: they can prompt a wider set of activities to help children become familiar with a food (through more engaging digital features) and they can be distributed on a large scale at little or no cost.

\section{Personalisation}

Mobile and online technologies providing personalised nutrition advice have shown great promise in improving dietary outcomes among adults (Forster et al. 2016). It is possible that incorporating personalised elements into e-book interventions could be equally effective in increasing fruit and vegetable intake among children.

Personalisation of e-books might take two different forms. Research has shown that considering individuals' goals and choices and tailoring intervention content to these can motivate greater changes in behaviour among adults (Ordovas et al. 2018). In the case of delivering e-book interventions, parents may benefit from being encouraged to identify their feeding goals during mealtimes, reflecting on their child's attitudes towards different foods and selecting the foods they would like their child to eat more of. Using such information to assign families a particular e-book or set of e-books offers a type of personalisation that is focused on 
the caregiver, and could be used to encourage the uptake of eating interventions for children among adult caregivers.

A second form of personalisation involves adapting e-books so that their content is related to the individual child reading it (e.g. e-books could include pictures of the child engaging with foods in their home environment). Personalisation is likely to increase children's engagement with and understanding of the information provided; it may also provide opportunities for more extended conversations about the content, based on parents' and children's shared experiences, knowledge and interests (Kucirkova 2017). Several studies have found positive effects of personalised books on parent-child interactions and child language outcomes. For example, Kucirkova et al. (2012) found that personalised books, in which photos and story content were tailored specifically to a child's activities and environments, elicited more smiles and laughs from children aged between 12 and 33 months than non-personalised books. In studies involving interactions between researchers and children, personalised books elicited more spontaneous utterances, questions, and comments among 17- to 55-month-olds (Kucirkova et al. 2014a) and better word acquisition among 35- to 56-month-olds (Kucirkova et al. 2014b) than nonpersonalised books.

To capitalise on the benefits associated with this second form of personalisation, supporting apps should be developed to enable the personalisation of fruit and vegetable e-books. Families could be encouraged to customise the e-book content by adding photos, text, audio recordings and videos that show family members growing or shopping for fruits and vegetables, washing and preparing foods at home, and eating them. By extension, encouragement to personalise e-books might lead to multisensory exposures to foods beyond the shared e-book reading activity, if the personalisation activities provide opportunities to touch, smell, and taste 
foods in addition to opportunities to gain visual familiarity (Dazeley et al. 2012). In sum, e-book interventions that offer a tailored experience to families, by aligning with their mealtime goals and preferences and by allowing personalisation of e-book content, have the potential to increase both parents' motivation to read e-books and children's engagement with both the books and real foods.

\section{The See \& Eat study}

Our group is currently exploring some of these possibilities within the See \& Eat project, a preregistered research study (http://osf.io/qjsdp). We are recruiting families with children aged 18 to 48 months to read one of 24 vegetable e-books showing the 'farm to fork' journey of a vegetable through pictures and text (see Figure 1 for an example e-book). The e-books are accessible on iPads or tablet devices using the Our Story 2 app developed by the Open University, the editing features of which allow both interactivity and personalisation.

The study aims to evaluate the effectiveness of vegetable e-book exposure on children's willingness to taste, intake and liking of a target vegetable chosen by their families with the expectation that, similar to printed storybooks, repeated e-book exposure will enhance children's acceptance of the targeted vegetable after two weeks. The study will also explore whether families take advantage of opportunities to make the e-books more interactive and personal using the editing features of the Our Story 2 app.

Interestingly, the majority of studies using picture books or picture-based exposure to promote fruit or vegetable consumption among children have been conducted in Englishspeaking countries, with the exception of studies by de Droog et al $(2014 ; 2017)$ and Rioux et al (2018). In studies where participant demographics have been reported (e.g. Heath et al, 2014; 
Owen et al, 2018; Rioux et al (2018), samples involved a majority of white and middle-class or relatively well-educated families (one exception being Byrne \& Nitzke, 2002). E-books have the potential to reach a large number of families across geographical locations and socioeconomic groups. The See \& Eat project is currently recruiting families in the UK and Italy, but future initiatives include expanding the availability of the app and the e-books into other European languages and into non-tablet based devices such as smartphones, enabling us to reach a wider range of ethnic, cultural, and socioeconomic profiles in future.

\section{Conclusions}

The effectiveness of picture book interventions to support children's healthy eating could be enhanced by digital technologies. E-books that introduce unfamiliar or disliked foods to children should be carefully designed to take advantage of features that support learning and engagement (e.g. narration) while avoiding elements that distract children from attending to the targeted foods (e.g. unrelated animations). Parents may not be familiar with the possibilities afforded by e-books and their supporting applications or devices; hence, additional guidance is needed to ensure that they engage fruitfully with the opportunities e-books afford. Supporting technologies could provide greater opportunities for personalisation of book content to support parents' goals in using e-books and to enable parents to select the foods they would like to introduce to their child. Finally, the incorporation of editing features that allow families to create customised fruit and vegetable stories might not only enhance children's engagement with the book content but might also prompt families to provide multisensory exposures involving looking, touching, smelling, and tasting the actual foods. Future research should, therefore, investigate the potential of e-books to deliver effective healthy eating interventions for children. 
Given the convenience and popularity of digital technologies in both home reading and nutrition interventions, e-book interventions open an exciting new avenue to reach families on a large scale. 


\section{References}

Barnes JL \& Warren CA (2017) Development of food group books for three- and four-year-old children. Family and Consumer Sciences Research Journal 45: 272-84.

Birch LL, McPhee L, Shoba BC et al. (1987) What kind of exposure reduces children's food neophobia?: Looking vs. tasting. Appetite 9: 171-8.

Byrne E \& Nitzke S (2002) Preschool children's acceptance of a novel negetable. Journal of Nutrition Education and Behavior 34: 211-4.

Carruth BR, Ziegler PJ, Gordon A et al. (2004) Prevalence of picky eaters among infants and toddlers and their caregivers' decisions about offering a new food. Journal of the American Dietetic Association 104: 57-64.

Coulthard H, Harris G \& Emmett P (2010) Long-term consequences of early fruit and vegetable feeding practices in the United Kingdom. Public Health Nutrition 13: 2044-51.

Coulthard H \& Sealy A (2017) Play with your food! Sensory play is associated with tasting of fruits and vegetables in preschool children. Appetite 113: 84-90.

Dazeley P \& Houston-Price C (2015) Exposure to foods' non-taste sensory properties. A nursery intervention to increase children's willingness to try fruit and vegetables. Appetite 84: 1-6.

Dazeley P, Houston-Price C \& Hill C (2012) Should healthy eating programmes incorporate interaction with foods in different sensory modalities? A review of the evidence. British Journal of Nutrition 108: 769-77.

de Droog SM, Buijzen M \& Valkenburg PM (2014) Enhancing children’s vegetable consumption using vegetable-promoting picture books. The impact of interactive shared reading and character- product congruence. Appetite 73: 73-80.

de Droog SM, Nee RV, Govers M et al. (2017) Promoting toddlers' vegetable consumption 
through interactive reading and puppetry. Appetite 116: 75-81.

Farrow C, Belcher E, Coulthard H et al. (2019) Using repeated visual exposure, rewards and modelling in a mobile application to increase vegetable acceptance in children. Appetite 141: 104327.

Forster H, Walsh MC, Gibney MJ et al. (2016) Personalised nutrition: The role of new dietary assessment methods. Proceedings of the Nutrition Society 75: 96-105.

Grimshaw S, Dungworth N, Mcknight C et al. (2007) Electronic books: Children's reading and comprehension. British Journal of Educational Technology 38: 583-99.

Heath P, Houston-Price C \& Kennedy OB (2011) Increasing food familiarity without the tears: A role for visual exposure? Appetite 57: 1-30.

Heath P, Houston-Price C \& Kennedy OB (2014) Let's look at leeks! Picture books increase toddlers' willingness to look at, taste and consume unfamiliar vegetables. Frontiers in Psychology 5: 1-11.

Hoppu U, Prinz M, Ojansivu P et al. (2015) Impact of sensory-based food education in kindergarten on willingness to eat vegetables and berries. Food \& Nutrition Research 59: 1-8.

Houston-Price C, Burton E, Hickinson R et al. (2009a) Picture book exposure elicits positive visual preferences in toddlers. Journal of Experimental Child Psychology 104: 89-104.

Houston-Price C, Butler L \& Shiba P (2009b) Visual exposure impacts on toddlers' willingness to taste fruits and vegetables. Appetite 53: 450-53.

Houston-Price C, Owen LH, Kennedy OB et al. (2019) Parents' experiences of introducing toddlers to fruits and vegetables through repeated exposure, with and without prior visual familiarization to foods: Evidence from daily diaries. Food Quality and Preference 71: 291300. 
de Jong MT \& Bus AG (2002) Quality of book-reading matters for emergent readers: An experiment with the same book in a regular or electronic format. Journal of Educational Psychology 94: 145-55.

de Jong MT \& Bus AG (2004) The efficacy of electronic books in fostering kindergarten children's emergent story understanding. Reading Research Quarterly 39: 378-93.

Kähkönen K, Rönkä A, Hujo M et al. (2018) Sensory-based food education in early childhood education and care, willingness to choose and eat fruit and vegetables, and the moderating role of maternal education and food neophobia. Public Health Nutrition 21: 2443-53.

Korat O \& Falk Y (2019) Ten years after: Revisiting the question of e-book quality as early language and literacy support. Journal of Early Childhood Literacy 19: 206-23.

Korat O \& Or T (2010) How new technology influences parent-child interaction: The case of ebook reading. First Language 30: 139-54.

Korat O \& Shamir A (2013) Expanding the boundaries of shared book reading: E-books and printed books in parent-child reading as support for children's language. First Language 33: $504-23$.

Kucirkova N (2017) Digital personalisation in early childhood. Bloomsbury Academic: London. Kucirkova N \& Littleton K (2016) The digital reading habits of children: A national survey of parents' perceptions of and practices in relation to children's reading for pleasure with print and digital books. Available at: http://www.booktrust.org.uk/news-and-blogs/news/1371 (accessed 28 October 2019).

Kucirkova N, Messer D \& Sheehy K (2014) Reading personalized books with preschool children enhances their word acquisition. First Language 34: 227-43.

Kucirkova N, Messer D \& Sheehy K (2014) The effects of personalisation on young children's 
spontaneous speech during shared book reading. Journal of Pragmatics 71: 45-55.

Kucirkova N, Messer D \& Whitelock D (2012) Parents reading with their toddlers : The role of personalization in book engagement. Journal of Early Childhood Literacy 13: 445-70.

Moody AK (2010) Using electronic books in the classroom to enhance emergent literacy skills in young children. Journal of Literacy and Technology 11: 22-52.

NatCen Social Center (2018) Health Survey for England 2017: Children's health.

Nekitsing C, Blundell-Birtill P, Cockroft JE et al. (2019) Increasing intake of an unfamiliar vegetable in preschool children through learning using storybooks and sensory play: A cluster randomized trial. Journal of the Academy of Nutrition and Dietetics, in press.

NHS (2018). Fussy eaters: Your pregnancy and baby guide. Available at: https://www.nhs.uk/conditions/pregnancy-and-baby/fussy-eaters/?tabname=babies-andtoddlers (accessed 1 November 2019).

Ordovas JM, Ferguson LR, Tai ES et al. (2018) Personalised nutrition and health. BMJ 361: 1-7. Owen LH, Kennedy OB, Hill C et al. (2018) Peas, please! Food familiarization through picture books helps parents introduce vegetables into preschoolers' diets. Appetite 128: 32-43.

Parish-Morris J, Mahajan N, Hirsh-Pasek K et al. (2013) Once upon a time: Parent-child dialogue and storybook reading in the electronic era. Mind, Brain, and Education 7: 200-11.

Rioux C, Lafraire J \& Picard D (2018) Visual exposure and categorization performance positively influence 3- to 6-year-old children's willingness to taste unfamiliar vegetables. Appetite 120: 32-42.

Roskos K, Burstein K, Shang Y et al. (2014) Young children's engagement with e-books at school: Does device matter? SAGE Open 4: 1-9.

Segal-Drori O, Korat O, Shamir A et al. (2010) Reading electronic and printed books with and 
without adult instruction: Effects on emergent reading. Reading and Writing 23: 913-30.

Smeets DJH \& Bus AG (2015) The interactive animated e-book as a word learning device for kindergartners. Applied Psycholinguistics 36: 899-920.

Strouse GA \& Ganea PA (2017a) Parent-toddler behavior and language differ when reading electronic and print picture books Frontiers in Psychology 8: 1-14.

Strouse GA \& Ganea PA (2017b) Toddlers' word learning and transfer from electronic and print books. Journal of Experimental Child Psychology 156: 129-42.

World Health Organization (2019) Global Strategy on Diet, Physical Activity and Health. Available at: https://www.who.int/dietphysicalactivity/childhood_diet/en/ (accessed 28 October 2019).

Zucker TA, Moody AK \& McKenna MC (2009) The effects of electronic books on prekindergarten-to-grade students' literacy and language outcomes: A research synthesis. Journal of Educational Computing Research 40: 47-87. 

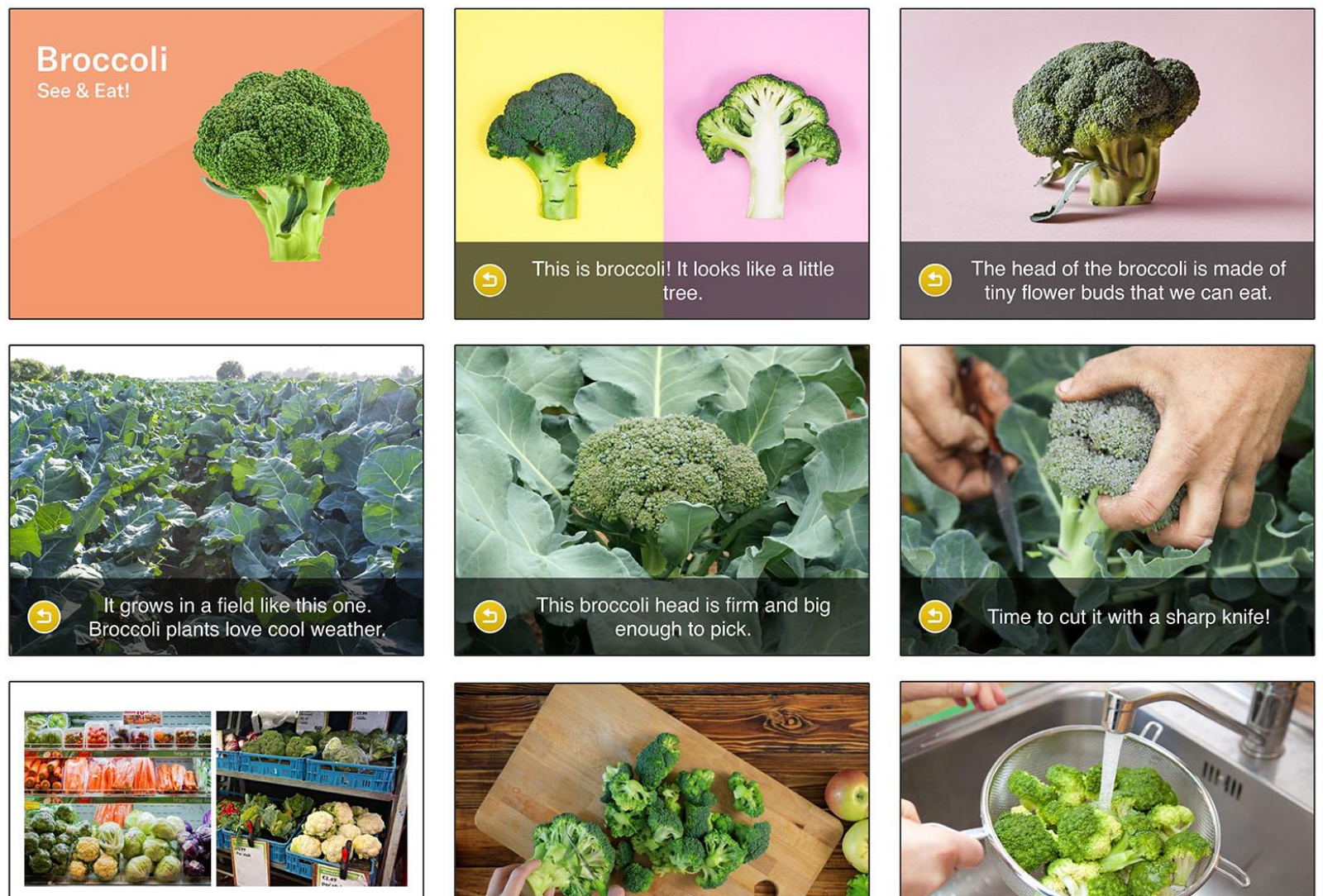

(9) You can buy broccoli in shops or in the market. Can you spot it?
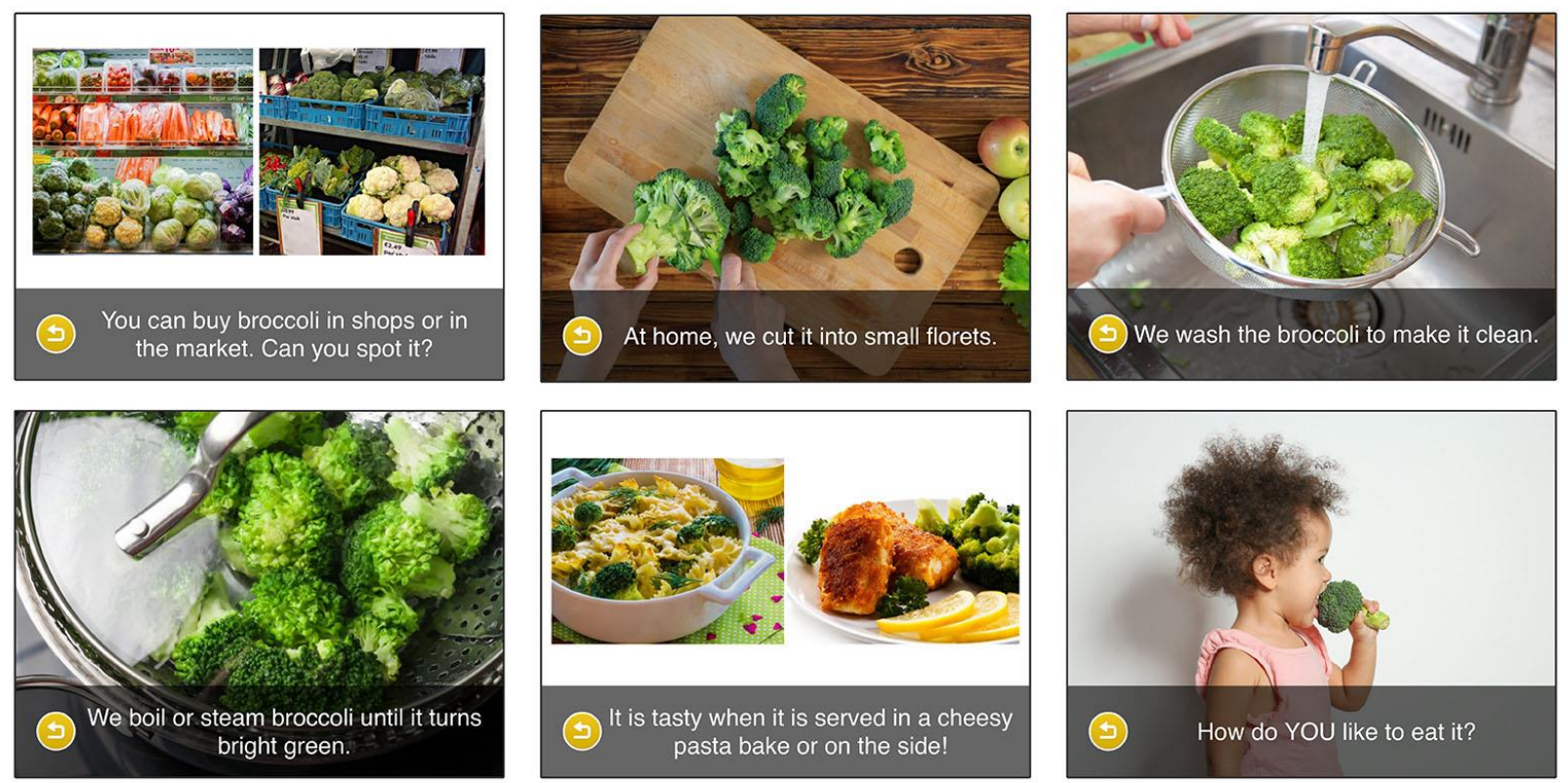

Figure 1. Example e-book about broccoli 